136 Copland, Med. Dic., N. Y., 1855, Vol. iii, p. 1321.

137 somerville, Iondon Lancet, 1887 , Tol. ii, p. 562

138 Iodid of potassium when given is retailied in the system until resolution begins, when it is passed with the urine. See Fox, op. cit resolution begins, when th is passed with the urine. See Fox, op. cit.,
p. 175:-Rigler, statistik d. Ineumonie, Wiener med. Wochenschr, 1858 ,

139 see Green, Quain's Dic. Med., X. Y., 1883, p. 877.

14) Semiotique des Urines, Paris, 1841.

141 London Iancet, 1884, Vol. i, p. 137

142 Op. cit., p. 175

143 Virchow Handb. Spec. Path. u. Therap., Bd. ii.

144 On the Urine, London.

1+5̌ Traité de l'Albuminurie, Paris, 1838.

$1 \% 6$ Pleuritis u. Pneumonie, Berlin, 1862

147 See Begbie, Ranking's Abst., 1852, No. 17, p. 102

148 'Thus of Fox's ten cases five died-50 per cent. : of Greisinger' sixty-three cases twenty-one died-33.3 per cent., and of Parkes' five case three died -60 per cent

49 Deutsche Med. Zeitung. 1883, Nr. 41

150 Kühn Arch. f. k. Med., Ba. xxi.

151 Nee also Kayer, Mal. des Reins, Paris, 1854, T. i, p. $578 ;-S t o r t z$

Inaug. Oissert. Noy

lingen, 1880:-Leube, Lehre vom Harn, Brlin

Fenwick, Lancet, 1891, 01 i, 248.

152 Memminger, $N$. Y. Med. Jour., Feb. 7, 1885, p. 159 . tels, Ziemssen's Handb. Spec. Path. u. Therap.;-Delafield, N. Y. Med. Res. Feb, 11, 1848 , p. 151 ;-Doubleday, ibid., March 28, 1885, p. 343;-Draper, ibid., Nov. 28, 1885, p. $614 ;-G i o v a n n 1$, Gaz. Méd. ital. Lombard., 1872;Wien, 1883 , s. 145;-MeDowell, Ranking's Abst.; 1856, No. 24, p. 65;Thompson, I.ondon Lancet. N. Y. 1857, Vol, ii, p. 194;-U. S. Marine H!ospt. Ripts., 1s\&4, p.

list Jelafield, N. Y. Med. Jour.. Oct. 6, 1883, p. 370

155 Jones, London Lancet, July 2,1870 .

156 Moore, N. Y. Med. Rec., Sept. 10, 1889, p. 31

$15 i$ see also Dana, N. Y. Med. Rec., Dec. 23, 1883, p. $696:-$ Frenomenow, Deutsche Ned. Zeitung, Mai, 8, 1854;-Gerhardt, Charite Ann., Bd, xili, 1888 ;-McBride, N. Y. Mled. Rec., Dec. 23,1883 , p. 696 ;-Pohl, Inaug. Diss.,
St. Petersburg, 1883 ;- - Whittaker, Phila. Med. News, Dec. 3, 1887, p. 641;-

iss Pohl, op. cit., having proven that the lung tissue has a peptic action, has adranced the Thenious theory that the fibrous exudut now, op cit.

159 See Fischel, Arch. f. Gynækologie, Bd, xxiv;-Frenomenow, op. Med. Jonr., leec. \&. 1883;-Jones, Ann. Chem u. Pharm., Bd. lxvii-Pietro, London Laticet, June 28,1884 , p. 1174 ; - et al

$16 \%$ When the iodid of potassium is given as a medicinal agent in pneumonic fever it is said to be retained in the system until resolution begins, when it is passed off through the urine. See Fox, op. cit., p. 175;-Rigler, Wiener Med. Wochensch, 1858, Nr. 48;-et al.

161 solon. op. eit., p. 138.

162 I have met with three cases. See also Andral, Med. Clin., Phila., 1843, Vol. ii, p. 199.

163 Guérin, Jour. Am. Med. Asso., Aug. 22, 1855, p. 216 ;-Lépine, op cit. ; Vaughn, Y'tomaines and Leucomaines, N. Y., 1888.

64 Vaughn, op. cit.

65 See Fox, op. cit., p. 175

66 Arch. f. expmt. Path., Bl. xx, s. 389

列

168 jerliner k. Woohenschr., 1886, s. 119

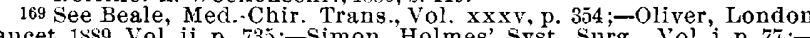

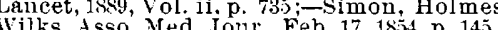

see Jacobi, Jour. A m. Med. Asso., April 3, 1886, p. 387

171 See Bagingky London Lancet, 1887, Vol. ii, p 492;-Ball, N. Y. lich. Rec., Sept. 1, 18s8;-Chautard, London Lancet, May 15, $1886 ;-\mathrm{E}$ r ensehr., 1884, Nr. 17;-Griffith, Phila. Med.aud Surg. Rep., Sept. 3. 1887; Jacobi, N. Y. Med. Rec., June 18, 1887, p. 696 ; - et al.

172 Muvs, Practitioner, Oct., 1887.

ii3 Hoffman, London MIed. Rec., Peb, 15, 1887.

175 See similar case reported by Harrington, $N$. Y. Med. Rec., July 9 , 1887 . 176 See Copland, op. cit.

177 U.S. Marine Hospt. Rpts., 1887, p. 248

\section{CARBUNCLE: ITS ETIOLOGY, PATHOLOGY AND TREATMENT.}

Read before the First Pan-American Medical Congress.

BY D. W. GRAHAM, A.B., M.D.

CHICAGO, ILL.

ATTENDING SURGEON TO PRESBYTERIAN HOSPITAL.

Carbuncle was formerly looked upon as a peculiar mysterious disease having a pathologic process of its own, with little or no relationship to any other disease, either in its etiology, its pathology, or its indications for treatment.

The teaching and especially the practice of the present day indicate that we are still in bondage to the traditions of the older pathology with respect to carbuncle, chiefly because it is one of those more common diseases which have received scant atten- tion in later years on account of the allurements of visceral surgery, and the rewards of work and study in the newer fields.

A conviction that there are established facts and available knowledge respecting this disease, which are not fully reflected in the views and the practice of to-day, is sufficient justification for an effort to ascertain and correlate what is known of the cause and nature of carbuncle, and for urging a more rational and radical method of treatment.

The observation has often been made and should be reiterated that the names, anthrax and malignant pustule, should no longer be used interchangeably with carbuncle. To avoid confusion the latter term sbould be reserved exclusively to designate the disease under consideration, while the former should be applied only to that disease of the lower animals which is contagious, sometimes communicated to man, and is caused by the anthrax bacillus.

Etiology.-Carbuncle is a disease of microbic origin, like all of its class. This has been demonstrated by the researches of Garrè, ${ }^{1}$ Bockhart,${ }^{2}$ Baum and others. The microörganism most frequently found is the staphylococcus aureus. In the minority of cases there are present also the staphylococcus albus or the streptococcus pyogenes, or the two together with the former, but always outnumbered by it. The coccus may enter the skin through the hair follicles, the sebaceous gland ducts, the sweat glands or an abrasion of the epidermis. ${ }^{2}$ The organism may enter also through the alimentary canal or the respiratory tract. We are nowhere more in bondage to the traditions of the elders than in the belief that this disease is of constitutional origin. The notion that it is a disease of the cachectic, the alcoholic, the tubercular and the diabetic was easily believed and necessarily prominent before local causes were demonstrated. The most that can be rightly claimed for the constitutional factor is that it increases the vulnerability of the tissues and predisposes to acute suppurations in general, rather than to carbuncle in particular. Even the diabetic, so prominently associated with carbuncle, does not of ten have the disease. The writer believes, with others, that the systemic vices are greatly overrated as etiologic factors, and though no statistics are at hand to prove it, it is even believed that the disease is not found more often, relatively, in the cachectic classes than in those of good health. The association of these constitutional conditions with carbuncle, in a causative relation, is probably partly accounted for by the fact that statistics used by writers and teachers have been collected more from the older large public hospitals and almshouses rather than from private practice and the smaller modern private hospitals. Whatever may be the exact facts in relation to this question it is certain that whoever ignores the local origin and local nature of the disease is handicapped and disarmed for the proper treatment of his patient.

Carbuncle is a disease of middle life, while its near relation, furuncle, is preëminently a disease of the adolescent, a clinical fact which is to be accounted for on the ground of histological variations in the skin at these periods of life as given below.

Anatomy and Pathology.-Nosologically, carbuncle is one of the acute suppurative inflammations of connective tissue, and hence is generically related to osteo-myelitis, parenchymatous abscess, acute abscess and furuncle, as well as other suppurative dis- 
eases of the skin. The essential unity of the group is shown when we consider that all have a local origin, all involve the same histologic structure, and all are due to the invasion of the same pus coccus; or at least one of the pyogenic cocci. The differences in clinical history, the divergence in pathologic process and the various modes of termination which are found when we compare the several diseases of this generic group with each other, are determined by differences in the anatomic structure of the region or organ concerned. These differences are quite as marked in the skin of different regions of the body when they are compared with each other, as are those found in one organ when compared with other organs. These variations in histologic anatomy relate to thickness, density, toughness, elasticity, vascularity, the surrounding attachments and the amount and mode of disposition of the adipose tissue.

It is these variations in histologic structure of the skin in different regions of the body, or the structural differences in the various strata of the skin in a given region, that determine whether in a given case of invasion by the pyogenic coccus we shall have a superficial pustulation, as impetigo; or a deeper and more extensive suppurative process, as furuncle; or a still more deeply seated and extensive one, as acute subcutaneous abscess, or carbuncle, as the case may be. When the coccus invades the month of the hair follicle, sebaceous gland or sweat gland, and is arrested there, we have impetigo ${ }^{2}$ or one of its congeners. There is little tension, no stasis, no obstruction to the outflow of fluids or pus and no slough.

When the deepest part of the epithelial structures of the follicle, or the sebaceous or sweat gland is invaded a true furuncle is the result. ${ }^{2}$ Here there is a degree of obstruction to the outflow of fluids and pus on account of the depth and partial closure of the passage way. Hence we have tension, stasis, liquification (pus), a limiting wall, and in the center a cone-like slough which consists of the remnants of the gland or follicle surrounded by as yet undigested connective tissue, especially fibers of the yellow elastic tissue.

But when the pus coccus passes beyond the epithelial layer of the skin into the cutis vera, the result is either an acute abscess ${ }^{2}$ with its circumscribed cavity filled with digested connective tissue and inflammatory products, or, on the other hand, a carbuncle with its dense infiltrated mass of undigested connective tissue, without any circumscribed cavity. Whether it be an abscess or a carbuncle will depend on the histologic structure of the skin of the particular region invaded. The region of predilection of carbuncle is "the dense and fibrous integuments over the posterior median line of the body." The skin of this region is characterized by :

1. Its extreme thickness, especially the relative thickness of the cutis vera.

2. The aponeurotic-like density of the papillary layer and its having few and small openings.

3 . The more direct connection of the subcutaneous tissue with the reticular part of the true skin, as one continuous structure.

4. The number and size of the polygonal spaces found in the subcutaneous and reticular strata, caused by the diverging and interlacing bundles of dense and not easily dissolved fibrous tissue which make up the framework of these strata. These polygonal spaces are chiefly occupied by adipos tissue constituting the paniculus adiposus, and a delicate network of fine easily digested connective tissue.

5. The presence of Warren's fat columns, extending from the adipose tissue below, to the base of the follicles of the lanugo hairs above, with their horizontal branches. ${ }^{3}$

6. The dense, tendon-like, cone-shaped fibrous bundles which extend from the base of the adipose columns obliquely to be inserted into the muscular fascia beneath.

The pus coccus having passed down and invaded these tissues, a focus of inflammation is begun and we have all the factors and conditions necessary for the production of a typical carbuncle. The delicate network of areolar adipose tissue succumbs readily and liquifies, and as tension increases pus is forced to the surface through the slender adipose columns into the hair follicles as the only means of escape. Thus we have the numerous pus points, and eventually the cribriform condition of the surface of the skin so characteristic of carbuncle 4 . As tension increases, the inflammation is forced to extend laterally further and further from the original focus through the polygonal spaces and channels occupied by the rapidly dissolving delicate connective tissue and fat. 'Thus we have the characteristic peripheral extension and the broad, flat indurated mass pressed between the still resisting dense papillary layer above, and the muscular fascia beneath, which are still firmly bound together by the tendon-like cones of fibrous tissue. If now an incision be made in to this mass there would be seen the numerous small pus points and channels but no proper pus cavity; both of which conditions are well-recognized features of carbuncle. The process continues until the skin over the original focus becomes necrotic and sloughs away, thus reducing the tension and peripheral pressure and we have the first step towards the natural limitation of the disease. But if this infiltration and induration have already extended so far as not to be influenced by this diminution of tension it will continue to spread indefinitely or until the sloughing process following in its wake has gained on it sufficiently to entirely arrest the peripheral tension. After all the longresisting, dense, fibrous parts described above, which began to die with the skin, have yielded and sloughed piecemeal, we have the crater-like cavity co-extensive with the indurated mass.

It is said carbuncle may occur on any part of the body, but this is not correct of true typical carbuncle conforming to a fixed definition. We can not have a typical carbuncle without continued surgical tension in inflamed tissues, one part of which resists the digestion or liquifying process of suppuration longer than other parts.

Many cutaneous inflammations are loosely called carbuncles, when they are simply abscesses. But as the characteristic features of the carbuncular skin are only typical in certain regions of the body, and are found more or less perfectly or imperfectly in other regions, it will often happen that a suppurative inflammation of the skin and subcutaneous tis. sue can not be definitely classed either as a carbuncle, an abscess or a furuncle; or that the characteristics of one predominate while those of the others are present in some degree.

Treatment.-The general indication for treatment is the same as in any other disease, viz.: To limit 
its extent and duration. The special indications are to arrest suppuration and to prevent septicemia.

The history of the means and methods of treating carbuncle would fill a volume. Palliative means are useful and to be recommended if nothing better can be done. Many good surgeons advocate a purely expectant course and discard all active means, relying on internal medication, and treating it as a selflimited disease, not to be interfered with. Most surgeons, however, recognize the necessity of doing something to hasten the sloughing in order to relieve tension, and thus limit the extent of the disease and prevent absorption of diseased products.

Caustics, incisions-single, multiple, subcutaneous and the time-honored crucial incisions are relied on. These are to be recommended, also, if nothing more efficient can be done, but they are all inadequate to fulfill the indications, although they accomplish something. Scraping, as advocated by Page and $\mathrm{Owen}^{5}$, and Mr. Teale, of Leeds ${ }^{6}$, and even the "excision and scraping" as advocated by Rushton Parker ${ }^{7}$ are valuable means in certain stages, after sloughing has begun. But these means are properly applicable only to those cases where the disease has ceased to extend, and are to be considered only as adjuvants to the incisions and caustics.

The injection of various antiseptics into the mass before sloughing has begun, as advocated by some, would hardly be relied upon by any one who had an adequate conception of the anatomy and nature of the disease. But it is not my purpose to review and compare discarded or prevalent methods. As a substitute for all of these, I would advocate total extirpation of the indurated mass, as we would remove a benign tumor. If this is done early the entire skin can be saved. If it is done later, there will be some loss of skin over the original focus but the patient will be saved from all the dangers of septicemia - the cause of death in carbuncle, usually miscalled exhaustion. If the patient already have septicemia and there remains a ring of indurated tissue beyond the sloughing center, extirpation is still the best means of saving the patient's life. It should be resorted to in all cases, whatever the stage of progress, except those in which the disease has clearly run its course, when the excision and scraping of Rushton Parker would be sufficient.

It is a rational, life-saving and time-saving method, and will commend itself to all who try it. All the reasons that call for amputation of a gangrenous limb can be urged in favor of total extirpation of carbuncle. The writer has practiced total extirpation in all suitable cases for the last five or six years.

The technique of the operation requires but few words. Anesthesia is required, which should be as brief as possible and not profound if the patient already suffers from septicemia.

A crucial incision should extend to just beyond the borders of the induration. The four flaps are to be dissected up to the limits of the disease, which can usually be made out easily, contrary to what is generally taught. Then with the volsella forceps and a knife the mass is readily dissected from its attachments to the deep fascia and removed entire or in sections, according to its size and condition. The four flaps are then stitched together toward the center, more or less closely, according to the amount of necrosis and sloughing. When the extirpation is done early, there will often be no loss of skin and but little subsequent discharge. There aro no blood vessels in or under the skin in the carbuncular regions that should terrorize any one.

LITERATURE.

1 Zur Atiologle der acut eitrigen entzündungen Fortschritte der Med. 1855 , No. 6 .

2 Bockhart, Monat Schefte für Prakt Dermat. IV, 1887, No. 10 3 Reference Handbook Medical Sciences Vol. II, Art. Columnæ diposæ.

4 J. Collins Warren, Boston Med. and Surg. Jour., April 19, 1877.

5 British Med. Journal March 24, 1888.

6 Medico-Chirurgical Journal, January, 1887

Tritish Med Journal, March 31, 1888.

UTRICULITIS ; A CONTRIBUTION TO THE PATHOLOGY OF THE PROSTATIC UTRICLE.

\section{BY WILLIAM T. BELFIELD, M.D.}

CHICAGO.

It is well known that the genital organs of the adult vertebrate are developed from two primitive organs of the embryo, the bodies named for Wolff and Müller; and that the sex of the individual varies with the relative development attained by these organs. In the future male animal the Wolffian duct furnishes the genital canal-epididymis and vas deferens-while the Müllerian duct suffers more or less complete atrophy; in the future female, on the other hand, the Müllerian duct furnishes the genital canal-Fallopian tubes, uterus and vagina (to the

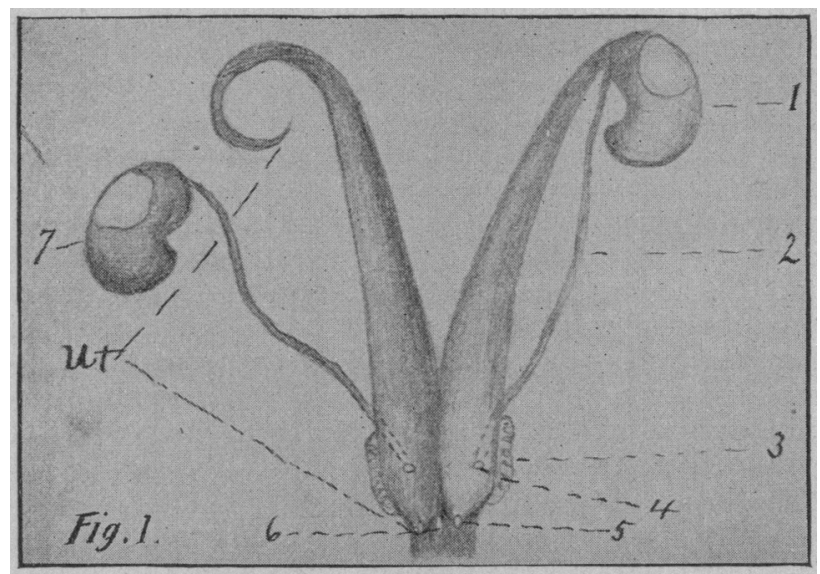

Fig. 1.-Internal genital organs of male guinea pig. 1, testicle; 2, vas deferens; 3 , seminal vesicle; 5 , orifice of vas deferens into uterus; 5 orifice of uterus into urethra; 6, verumontanum; 7, testicle displaced duct). Prostate not represented.

hymen) - the corresponding portions of the Wolffian duct suffering atrophy. In the most highly organized mammals, the male genital canal acquires certain accessory sexual glands not constantly found in the lower vertelurates-seminal vesicles, prostate, Cowper's, urethral and preputial glands-while the Müllerian duct exhibits marked atrophy; in man there persist regularly only the two rudimentary extremities of this duct, the hydatid of the testicle and the prostatic utricle.

Yet in some species the Müllerian tract retains in the male, side by side with the fully developed Wolffian canal, a high degree of elaboration; among the many species of mammals that I have personally dissected, none presents a clearer picture of the complete Müllerian duct in the male than the familiar guinea pig. In this animal the testicles are abdominal organs, lying somewhat below the kidneys; the usual organs of the male mammal are well developed, but in addition there are found two large 